\title{
Extraoral Extraction of an Impacted Molar Using Bone Lid Technique
}

\author{
Gökhan Göçmen, Altan Varol, Selçuk Basa, Kamil Göker
}

\begin{abstract}
We present a simple technique to keep the integrity of the lateral cortical wall after extraction of deeply impacted tooth located at the lower border of the mandibular base.

Keyworks: Bone-lid, impacted molar, extra-oral, extraction, tooth.

\section{Introduction}

The bone lid technique was first developed as a bone-saving method for surgical endodontic treatment of mandibular molars (1). Application of this tecnique was evolved to enucleate cysts or benign odontogenic tumours, to extract deeply impacted teeth, for maxillary sinus surgery and even to explant a fractured or failed osseointegrated dental implants (2-5).We present this simple technique to keep the integrity of the lateral cortical wall after extraoral extraction of deeply impacted tooth located at the lower border of the mandibular base.
\end{abstract}

\section{Case Report}

A-32-years-old male patient with a deeply impacted left mandibular first molar, which had caused infection and swelling 4 weeks ago, was operated under general anesthesia (Figure 1). Extra-oral submandibular approach was performed. To extract and keep integrity meanwhile, a bone lid was constituted. The bone lid is outlined with a small round burr. The holes are joined using a chisel, and the bony lid is removed (Figure 2). After extraction, formed lid was put back to its proper position and fixated with a $2.0 \mathrm{~mm}$ profile trauma plate (Trimed, Turkey)(Figure 3 ). The patient did not experience any paralysis of the facial nerve postoperatively.

Department of Oral \& Maxillofacial Surgery, Faculty of Dentistry,

Marmara University, Istanbul, Türkiye

Corresponding Author:

Gökhan Göcmen

Marmara University Dentistry Faculty

Buyukciftlik Sk. No: 6 Nisantasi-Istanbul, Türkiye

Tel : : (+90) 5324884368

Fax : : (+90) 2122465247

E-mail : gocmengokhan@hotmail.com
Figure 1. A sagittal plane of CT scan. Note the location and relationship with lower border of the mandibular base

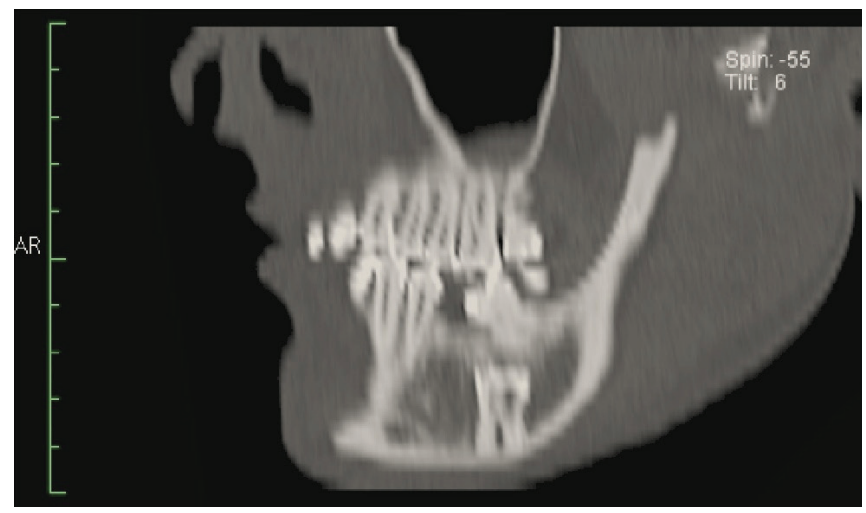

Figure 2. View of the raised bone lid and the molar tooth

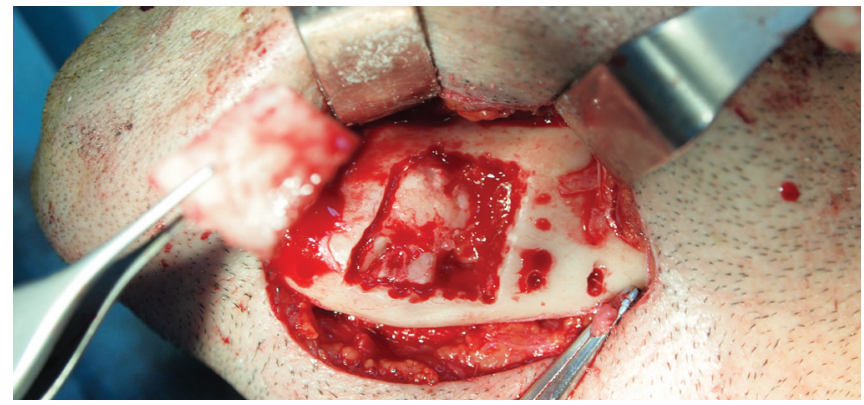

Figure 3. View of repositioned bone lid and fixation with the plate.

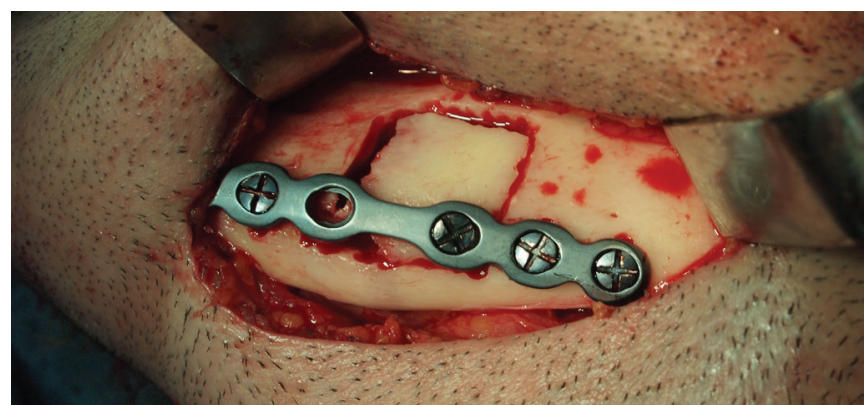




\section{Discussion}

Decision making for the surgical approach and technique to remove a deeply impacted tooth should be made according to its position between the cortices and relation to mandibular canal (6) Limited visibility, difficult intraoral access, excessive bone loss, and lack of complete removal are the main disadvantages of intraoral approach (7). Unfavorable splits and putting the occlusion at risk are also undesired complications of unilateral saggital split osteotomy to extract deeply impacted tooth (8). Extraoral approach presents good exposure of the surgical site, less colateral damage to bone integrity, more control over the surgical plane, and a lower probability of fractures. However possible injury to the facial nerve and the cosmetic sequelae of skin scar are the main disadvantages (6). In this case, we preferred extraoral approach due to position of the molar tooth, which was located on the cortical plate of mandibular basis. The bone lid was raised to prevent any bone grafting by putting back the lid to its original place.Bone lid technique presents quick recovery and restored integrity of the lateral cortical wall, with a low risk of infection due to extraoral approach and being covered by several tissue planes (3). Keeping the integrity of bone with this tecnique can block migration of epithelium into the large defect and constitute a framework for ossification, rather than lavishing considerable amounts of buccal cortical bone with conventional methods. So, bone volume could be shielded and hindered from large deficiencies after removal of such ectopic teeth.

\section{References}

1. Abu-El Naaj I, Braun R, Leiser Y, Peled M, 'Surgical Approach to Impacted Mandibular Third Molars--Operative Classification. J Oral Maxillofac Surg. 2010;68(3): 628-33

2. Degerliyurt K, Akar V, Denizci S, Yucel E. 'Bone Lid Technique with Piezosurgery to Preserve Inferior Alveolar Nerve. Oral Surg Oral Med Oral Pathol Oral Radiol Endod. 2009; 108(6): e1-5

3. Khoury F, Hensher R. The Bony Lid Approach for the Apical Root Resection of Lower Molars, Int J Oral Maxillofac Surg 1987; 16(2), 16670.

4. Mehra P, Castro V, Freitas R. Z, Wolford L. M. Complications of the Mandibular Sagittal Split Ramus Osteotomy Associated with the Presence or Absence of Third Molars, J Oral Maxillofac Surg. 2001; 59(8): 854-8.

5. Perkins N.J, Khoury F. P45 a Conservative Method for Removal of Osseointegrated Dental Implants - the Bony Lid Technique., Br J Oral Maxillofac Surg 2010; 48 36-37.

6. Savitha K, Cariappa K.M. An Effective Extraoral Approach to the Mandible. A Technical Note', Int J Oral Maxillofac Surg, 1998;21: 61-2.

7. Tay A.B. Buccal Corticotomy for Removal of Deeply Impacted Mandibular Molars', Br J Oral Maxillofac Surg. 2007;45:83-4.

8. Widmark G, Ekholm S, Borrman H, Grangard U, Holmberg K. The Use of a Bone Lid to Close the Anterior Wall Defect after Surgery in the Maxillary Sinus, Swed Dent 1992; 16:173-82. 